\title{
Research Article \\ Effect of the Prodegradant-Additive Plastics Incorporated on the Polyethylene Recycling
}

\author{
Miguel Aldas (D), Andrea Paladines, Vladimir Valle (D), \\ Miguel Pazmiño, and Francisco Quiroz
}

Departamento de Ciencia de Alimentos y Biotecnología, Facultad de Ingeniería Química y Agroindustria, Escuela Politécnica Nacional, Quito, Ecuador

Correspondence should be addressed to Miguel Aldas; miguel.aldas@epn.edu.ec

Received 5 September 2017; Revised 1 December 2017; Accepted 26 December 2017; Published 24 January 2018

Academic Editor: Cornelia Vasile

Copyright (c) 2018 Miguel Aldas et al. This is an open access article distributed under the Creative Commons Attribution License, which permits unrestricted use, distribution, and reproduction in any medium, provided the original work is properly cited.

The effect of degraded plastic with prodegradants on the polyethylene properties was studied. First, the mixture of low-density polyethylene (LDPE) with $5 \mathrm{wt} . \%$ prodegradant (oxo-degradable) additive was prepared by melt processing using a mixer chamber. Then, the degradation of the mixtures was evaluated by exposing the oxo-degradable LDPE in a Xenon arc chamber for 300 hours. The degraded material was characterized by infrared spectroscopy (FTIR) assessing the carbonyl index and the hydroperoxide band. Then, different percentages of degraded material $(1,5,10,20$, and $50 \mathrm{wt} . \%)$ were incorporated into the neat LDPE. Mechanical and rheological tests were carried out to evaluate the recycling process of these blends. Also, the feasibility of the blends reprocessing was determined by analysing the melt flow index for each heating process and shear stress applied. It was evidenced that the increment of the content of the degraded material in the neat LDPE decreased the mechanical strength and the processability of blends due to the imminent thermal degradation. All the test results showed that the incorporation of degraded material causes a considerable reduction in the matrix properties during the reprocessing. Nevertheless, at low concentrations, the properties of the oxo-degradable LDPE-LDPE blends were found to be similar to the neat LDPE.

\section{Introduction}

Since the discovery and development of plastic materials, many needs have been fulfilled. At the same time, the increasing amount of waste generated by the use of plastics has become a significant issue. Several countries have begun to face the problem by implementing restrictive and regulatory laws regarding the production and use of plastics. New formulations of polymers have been proposed to obtain degradable materials whose final ecological and physical footprint is much smaller $[1,2]$.

Polymeric materials have been consumed on a massive scale due to their processability, excellent properties, and high durability in various uses [3]. Initially, due to their outdoor durability, polymers were considered as an alternative to replace other types of materials [4]. Currently, the mentioned advantages have also caused an adverse environmental impact which is evidenced in landfills with a massive volume of plastic waste $[5,6]$.
Plastic waste processing has been carried out using various postconsumer treatments such as recycling (mechanically or chemically), energy recovery through incineration or pyrolysis, and aerobic and anaerobic biological processing [7]. However, these procedures, from recollection to classification, can be expensive and complicated. For this reason, the plastic industry has decided to venture into the fabrication of degradable materials whose purpose lies in the reduction of the plastics lifespan in their final disposal $[6,8]$.

At the industrial level, in the field of degradable polymers, research has been carried out on the development of biodegradable and oxo-degradable plastics $[9,10]$. Biodegradable polymers are materials that are compatible with a biological medium because they can be used as an energy source by microorganisms such as bacteria and fungi. As a result of this interaction, $\mathrm{CO}_{2}$ and methane are produced in aerobic and anaerobic environments, respectively [11, 12].

Oxo-degradable materials are polyolefins with a prooxidant additive, in amounts of 1 to $5 \%$ by weight, and are 
produced using metallic salts of iron, magnesium, nickel, and cobalt. The metallic components catalyse the oxidation of the polymer causing ruptures in the long-chain molecules and a reduction in the size of the material [13]. It is worth mentioning that, for these types of plastics to be considered as biodegradable, their biodegradation must be no less than $90 \%$ after the assimilation time limits have elapsed according to the European standard EN13432. According to this standard, oxo-degradable plastics are not entirely considered biocompatible [14, 15].

Oxo-degradable additives are commonly incorporated in polyolefins such as the highly used polyethylene (PE) and polypropylene (PP) [16]. The reaction mechanism of the oxodegradable additives is based on the oxidative degradation of the material through the reaction of the molecular oxygen present in the atmosphere with free radicals generated in the polymer molecule by light and heat $[17,18]$

The oxo-degradation is an abiotic process and, thanks to the incorporation of oxygen in the polyethylene molecule, functional groups that contribute to the generation of peroxides and hydroperoxides are formed. This effect can be measured by the carbonyl content [13]. As a result of the oxidation, the characteristics of the polymer change from hydrophobic to hydrophilic, giving rise to fragmentation in the material and the subsequent absorption of moisture [19]. The carbonyl groups, which are products of the reaction of radicals generated by the oxidation of the material additive, cause the splitting of the polymer chains, as stated by Chiellini et al. (2006) [18], altering the mechanical properties of the material considerably.

The imminent degradation, as a result of the action of oxo-degradable additives, has made these types of material nonrecyclable [20]. Also, the lifespan of the oxo-degradable polyolefins depends on polymeric chains (unsaturated or branched) and their susceptibility to capture oxygen. For this reason, HDPE is considered to be one of the best materials for postconsumer production. However, low-density polyethylene (LDPE) is commonly used in the development of oxodegradable products such as plastic bags [18].

This study evaluates the feasibility of incorporating oxodegradable LDPE into a neat polymer as well as the maximum level of reprocessing that can be withstood by the polyolefin blends before the degradation process starts.

\section{Experimental}

2.1. Materials. A film grade LDPE from Dow Chemical Company (Michigan, USA) and an oxo-degradable $\mathrm{d} 2 \mathrm{w}$ additive based on polyethylene resin from Symphony Environmental (Borehamwood, UK) were used as raw materials. Both materials were stored in $25 \mathrm{~kg}$ bags at environmental conditions of Quito, Ecuador. The technical specifications of each material are shown in Table 1.

\subsection{Methodology. The methodology is described as follows:}

(i) Formulation of the oxo-degradable LDPE

(ii) Controlled degradation of oxo-degradable LDPE films in a Xenon arc chamber
TABLE 1: Technical specification of neat LDPE and oxo-degradable additive.

\begin{tabular}{|c|c|}
\hline Property & Value \\
\hline \multicolumn{2}{|l|}{$L D P E^{*}$} \\
\hline Appearance & Beige pellet \\
\hline Melt flow index [190/2,16 kg: g/10 min] & 2 \\
\hline Apparent density $[\mathrm{g} / \mathrm{l}]$ & 800 \\
\hline Specific gravity & 1,9 \\
\hline Moisture content [ppm] & $<2000$ \\
\hline \multicolumn{2}{|l|}{ Additive $d 2 w^{* *}$} \\
\hline Vicat temperature $\left[{ }^{\circ} \mathrm{C}\right]$ & 95 \\
\hline Appearance & White pelle \\
\hline Melt flow index [190/2,16 kg: g/10 min] & 2 \\
\hline Density $\left[\mathrm{g} / \mathrm{cm}^{3}\right]$ & 0,922 \\
\hline
\end{tabular}

${ }^{*}[22],{ }^{* *}[23]$.

(iii) Characterization of the aged oxo-degradable LDPE

(iv) Formulation of the blends with neat LDPE and aged oxo-degradable LDPE

(v) Assessment of the mechanical recycling of the final product.

2.2.1. Formulation of Oxo-Degradable LDPE. LDPE was mixed with the oxo-degradable additive at $5 \mathrm{wt} . \%$. The blend was prepared in an internal torque mixer Thermo Fisher Scientific Haake chamber, model Polylab System (Karlsruhe, Germany), and the conditions were selected from the processing of the neat LDPE. Two trials at five different temperatures $\left(120,130,140,150\right.$, and $\left.160^{\circ} \mathrm{C}\right)$ and two mixing times $(2$ and $4 \mathrm{~min}$ ) were carried out. The optimal temperature and time conditions for mixing LDPE were determined based on a $2 \times 5$ factorial experimental design and the coloration analysis of the product. These conditions were $150^{\circ} \mathrm{C}$ and 4 minutes. As a result, a homogeneous blend was obtained as shown in Figure 1 and reduced to smaller particle size (less than $2 \mathrm{~mm}$ ) using a blade grinder machine. $0.3 \mathrm{~mm}$ thick films were obtained from the ground blend using $10 \mathrm{~cm} \times$ $10 \mathrm{~cm}$ moulds and a Carver heated hydraulic press, model 2112 (Menomonee, USA), at $4 \mathrm{lbf}$ for one minute.

2.2.2. Controlled Degradation of the Oxo-Degradable LDPE. The influence of ultraviolet light on the $5 \mathrm{wt} \%$ oxo-degradable/LDPE additive was evaluated using a Xenon arc chamber Q-Lab model Xe-1 (Florida, USA). The films previously obtained were exposed to $63^{\circ} \mathrm{C}$ and $0,35 \mathrm{~W} /\left(\mathrm{m}^{2} \cdot \mathrm{nm}\right)$ at $340 \mathrm{~nm}$ as stated by the ASTM D5071-06 standard for $330 \mathrm{~h}$. The samples were exposed to a continuous UV-light cycle without water spray [12].

2.2.3. Assessment of the Oxo-Degradable LDPE Degradation. Quantitative and qualitative assessments were performed using a Perkins Elmer FTIR spectrophotometer, model Spectrum One, in the range of 4000 to $600 \mathrm{~cm}^{-1}$, with a resolution of $4 \mathrm{~cm}^{-1}$ and 20 scans. The maximum degradation time of the films was determined by two FTIR methods: horizontal 


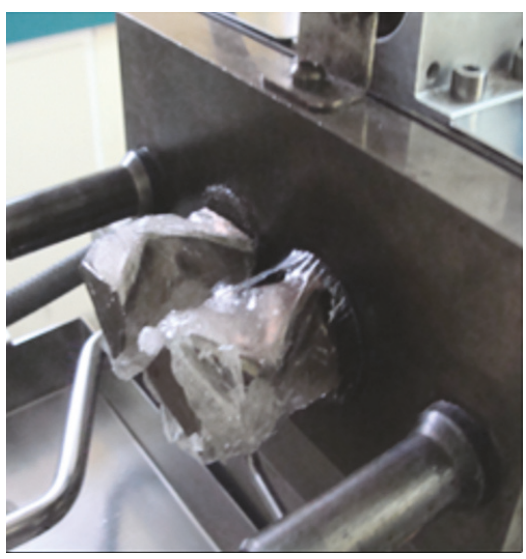

(a)

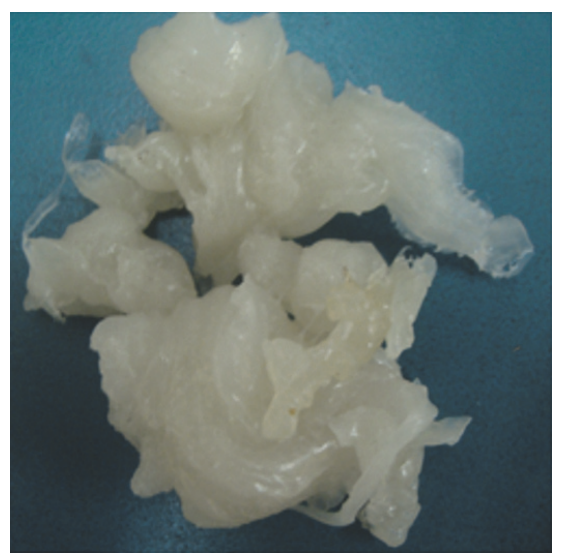

(b)

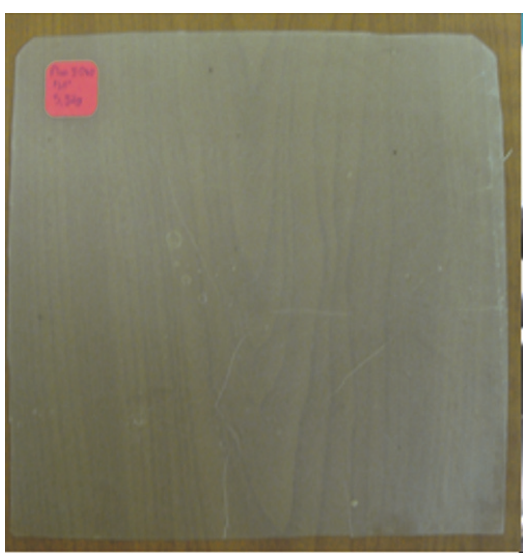

(c)

FIGURE 1: Process to obtain the prodegradant additive/LDPE films. (a) Internal torque mixer, (b) homogeneous mass of mix, and (c) final film obtained.

attenuated total reflectance (HATR) and transmittance. Data were obtained at 50,110, 160, 210, 260, 300, and 330 hours of testing in the degradation chamber.

The qualitative assessment was performed by overlapping HATR spectra of the sample at different exposure times and comparing the carbonyl bands at $1,713 \mathrm{~cm}^{-1}$ and the hydroperoxides bands between 3,600 and $3,200 \mathrm{~cm}^{-1}$. These parameters determined the degradation level $[13,21]$.

The quantitative assessment in this work was performed by calculating the carbonyl index of the samples using (1), adapted from Roy et al. (2007) [24]. This equation relates the area of the carbonyl band at $1713 \mathrm{~cm}^{-1}$ with the area of a reference band at $2,019 \mathrm{~cm}^{-1}$, which corresponds to a band in the spectrum that remains constant despite the degradation of the polymer. For this assessment, transmittance FTIR spectra were used. The Spectrum ${ }^{\mathrm{TM}}$ v.5.01 software allowed determining the total and corrected area of the carbonyl and the reference bands in the transmittance spectra. The total area was calculated from the area between the $x$-axis and the carbonyl band. The corrected area was calculated from the area between the baseline of the spectrum and the carbonyl band. Baseline correction and spectrum normalization were made using the Spectrum v.5.01 software to every FTIR spectrum, according to ASTM E168-16 Standard.

$$
I_{\mathrm{C}}=\frac{A_{\mathrm{c}}}{A_{\text {ref }}}-I_{\mathrm{C}_{o}},
$$

where $I_{\mathrm{C}}$ is carbonyl index of the exposed sample,

$I_{\mathrm{C}_{o}}$ is carbonyl index of the sample before degradation [25],

$A_{\mathrm{c}}$ is area of the carbonyl band,

$A_{\text {ref }}$ is area of the reference band $\left(2,019 \mathrm{~cm}^{-1}\right)$.

2.2.4. Formulation of the Neat LDPE with Aged Oxo-Degradable LDPE. Once the maximum exposure time for degradation was determined, a batch of oxo-degradable LDPE films was degraded and incorporated into the neat LDPE matrix. The mixture was prepared using an internal mixer chamber at the conditions determined in Section 2.2.1. The blends were formulated at 1, 5, 10, 20, and $50 \mathrm{wt} . \%$ of degraded LDPE.

2.2.5. Assessment of the Final Product Mechanical Recycling. Recycling of the oxo-degradable LDPE with different percentages of the neat LDPE was evaluated following the methodology described below:

(1) Degraded material/LDPE films (1, 5, 10, 20, and 50 wt.\%) were obtained by hydraulic compression moulding. Specimens of $100 \mathrm{~mm} \times 10 \mathrm{~mm}$ were cut from the films. The average thickness of the samples was $0.3 \mathrm{~mm}$.

(2) To study the influence of the oxo-degradable additive on the LDPE mechanical properties, tensile tests were carried out in an Instron universal test machine, model 1011 (Norwood, USA), at room temperature according to the ASTM D882-12 Standard. A $5 \mathrm{kN}$ load cell was used for all the tests at $50 \mathrm{~mm} \mathrm{~min}^{-1}$ crosshead speed. At least five different specimens were tested to obtain mean values.

(3) To evaluate the mechanical recycling process, a thermal analysis of the blends was carried out in a Netzsch differential scanning calorimeter (DSC), model F1 Phoenix, in nitrogen atmosphere $\left(50 \mathrm{~mL} \mathrm{~min}^{-1}\right)$, at

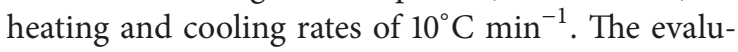
ation of the melting temperature allowed estimating the ideal temperature to reprocess the blends. Two heating cycles were used for each blend. The samples were first heated from room temperature to $180^{\circ} \mathrm{C}$ to eliminate their thermal history and then cooled to $30^{\circ} \mathrm{C}$ and immediately reheated from $30^{\circ} \mathrm{C}$ to $180^{\circ} \mathrm{C}$. Melting temperature $\left(T_{\mathrm{m}}\right)$, endset temperature $\left(T_{\text {endset }}\right)$, and the degree of crystallinity $\left(X_{C}\right)$ were determined from the second heating DSC curves. The 


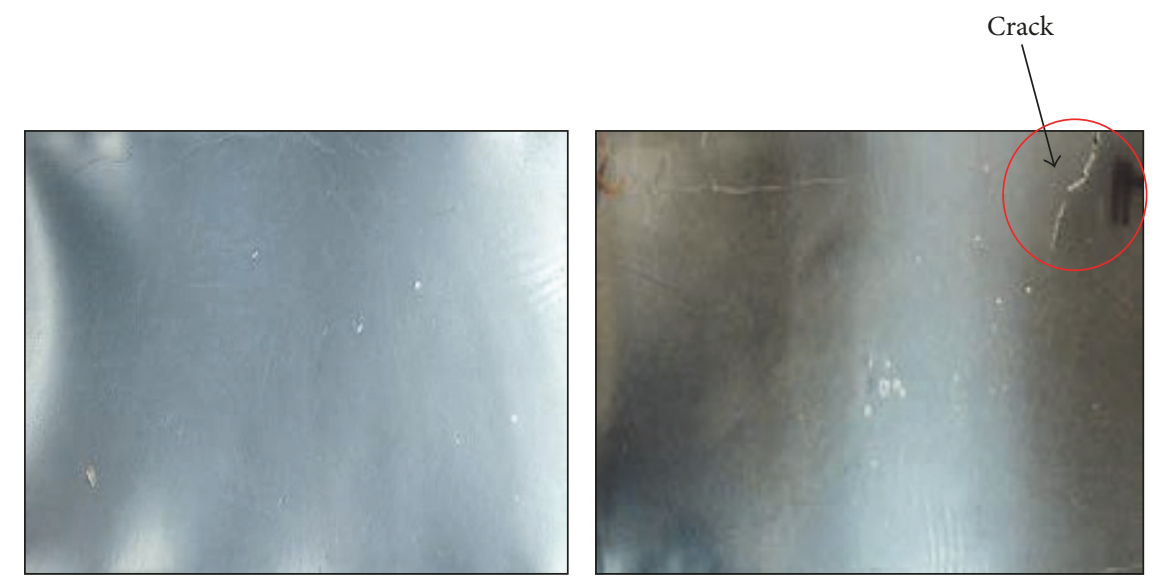

FIgURE 2: Oxo-degradable LDPE films at 0 and 330 hours of UV exposure in a Xenon arc chamber.

degree of crystallinity of each blend was calculated according to the ASTM D3418-15 Standard.

(4) Then, each degraded material/LDPE blend was subjected to shear stresses using the internal mixing chamber at $5^{\circ} \mathrm{C}$ higher than the endset value (temperature at which the melting process finishes) indicated by the DSC traces of the blends.

(5) $2.5 \mathrm{~g}$ of the processed mixtures was used to determine the melt flow index (MFI) in a Ceast Melt Flow Indexer, model 6942.000 (Torino, Italy), according to the ASTM D1238-13 Standard.

(6) Finally, the blends were reprocessed in the mixer chamber three times, and thermal analysis was carried out on each reprocessed product.

To achieve a pattern of comparison, the MFI of the reprocessed LDPE and the no-aged oxo-degradable LDPE were determined. The reprocessing of LDPE was useful to estimate the point at which the material does not withstand further processing. The MFI values of the different reprocessing were compared.

\section{Results and Discussion}

3.1. Assessment of the Oxo-Degradable LDPE Degradation. The degradation level of the oxo-degradable LDPE was determined by two factors: (1) the carbonyl index and (2) the formation of the hydroperoxides bands on the material spectra. Based on these analyses, $300 \mathrm{~h}$ of exposure time was set as the maximum limit time for the assessed formulations, before degradation is reached.

The crack formation and the change of the surface color in the oxo-degradable LDPE film can be observed in Figure 2. These two parameters showed the UV-exposed material deterioration. The $300 \mathrm{~h}$ cycle was determined by the quantitative and qualitative assessments of the degradation level as explained below.

3.1.1. Qualitative Assessment. The length of the exposure cycle was determined by the FTIR spectra analysis. At $330 \mathrm{~h}$, an intense band formation in the hydroperoxides zone was observed. Also, a crack formation of the film surface was evidenced. The hydroperoxides band formation is showed in Figure 3.

As can be seen in Figure 2, at $330 \mathrm{~h}$ of exposure, the oxo-degradable LDPE films exhibited high fragility leading to a film fragmentation and yellowing effect on the surface. This ageing effect, caused by the UV light of the Xenon arc chamber, prevents the film from further recycling processes. Consequently, for next assessments, the films were extracted from the UV chamber at $300 \mathrm{~h}$, that is, before the enhancement of the hydroperoxide band. The proliferation of the hydroperoxide group was established as the degradation limit before the extreme material fragmentation and reticulation occur $[25,26]$.

The degradation level at $300 \mathrm{~h}$ of exposure provided information regarding the material's ability to be reprocessed and recycled. However, it is important to emphasize that the degradation was an induced simulated process in the Xenon arc chamber, as the environment effect on the material was desired. A comparative FTIR analysis between neat LDPE and oxo-degradable LDPE films, both of them exposed in the Xenon arc chamber for 300 h, can also be seen in Figure 3.

The prodegradant additive in the LDPE influences the degradation level. The band at $1,713 \mathrm{~cm}^{-1}$ shows the formation of carbonyl groups which are originated by the polymer chains rupture. It can be seen in Figure 3 that the carbonyl zone of the oxo-degradable LDPE (red line) is more intense than that of the LDPE (black line), at the same time of the UV-light exposure. This means that the polymer chains experienced a structural damage leading to a superficial crack formation as evidenced in Figure 2. A noticeable difference in the hydroperoxides band intensity is also observed after $300 \mathrm{~h}$ of exposure. Furthermore, the action of the prodegradant on the polymer requires an initiator to form chromophores groups such as the carbonyl and hydroperoxide groups [12]. Thus, the additivated LDPE obtained does not present a significant degradation. Consequently, the gradual increase of the carbonyl bands in the whole range of exposure time until $300 \mathrm{~h}$, while the hydroperoxides band remains invariable, can be seen in Figure 4. 


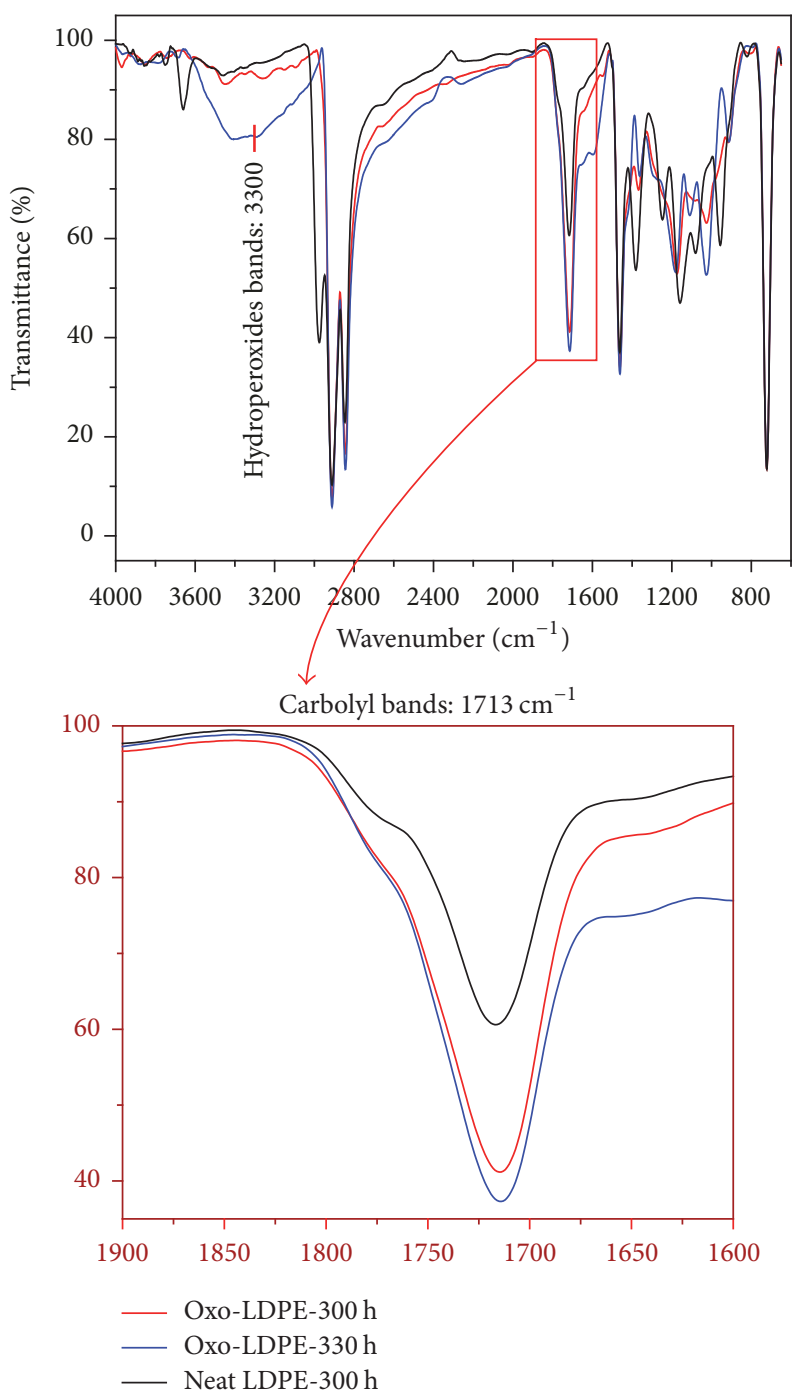

FIGURE 3: Comparative FTIR spectra for the carbonyl and hydroperoxides bands evolution in time for oxo-degradable LDPE and LDPE exposed in a Xenon arc chamber.

3.1.2. Quantitative Assessment. The carbonyl index was calculated using the total and the corrected area under the carbonyl bands, to have a quantitative reference to follow the degradation trend. The variations of the carbonyl index with time are depicted in Figure 5. Results show that values obtained with the corrected area have higher standard deviation compared to those calculated with the total area, perhaps due to the baseline corrections made to the spectra. However, it is evidenced that the carbonyl index values increase with exposure time in both results $[8,13]$. The carbonyl index mean value determined during the $300 \mathrm{~h}$ of Xenon arc chamber exposure was 6,47 for the total area and 45,3 for the corrected area. Data obtained with the total area showed lower dispersion.

\subsection{Mechanical Recycling of the Final Product}

3.2.1. Tensile Properties of the Degraded Material/LDPE Blends. The tensile strength and elongation at break of the

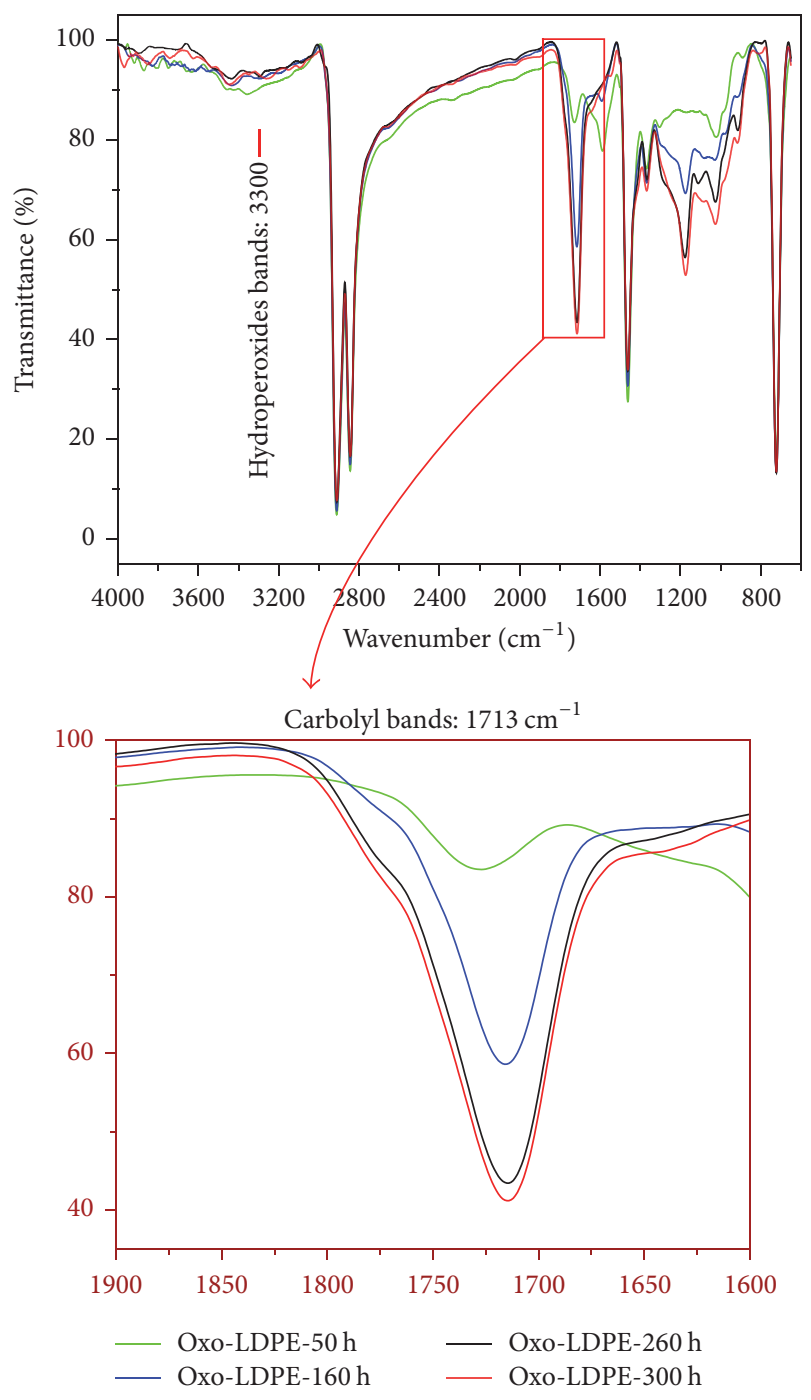

FIGURE 4: Carbonyl and hydroperoxides bands evolution in time of exposure in a Xenon arc chamber for oxo-degradable LDPE films studied by FTIR.

mixtures decrease as the degraded material concentration increases. This effect is originated by the chains breakage process caused by UV oxidation, which alters the LDPE mechanical properties. The incorporation of the additive causes an imminent loss of mechanical properties as shown in Table 2.

The incorporation of the aged oxo-degradable LDPE decreases by more than $50 \%$ the pure LDPE mechanical properties. This effect is observed in the whole range of concentrations even for low degraded material content such as $1 \mathrm{wt} . \%$ and $5 \mathrm{wt} . \%$. Additionally, the elongation at break is much more affected by the addition of the degraded LDPE in comparison to the tensile strength. This behavior is associated with the material crosslinking as the polymeric chain branches and ruptures increase due to the action of the UV-activated additive [14]. The influence of the degraded material incorporation on the neat LDPE is seen in Figure 6.

In this figure, it is shown that the tensile strength at break drops drastically with the incorporation of the degraded 


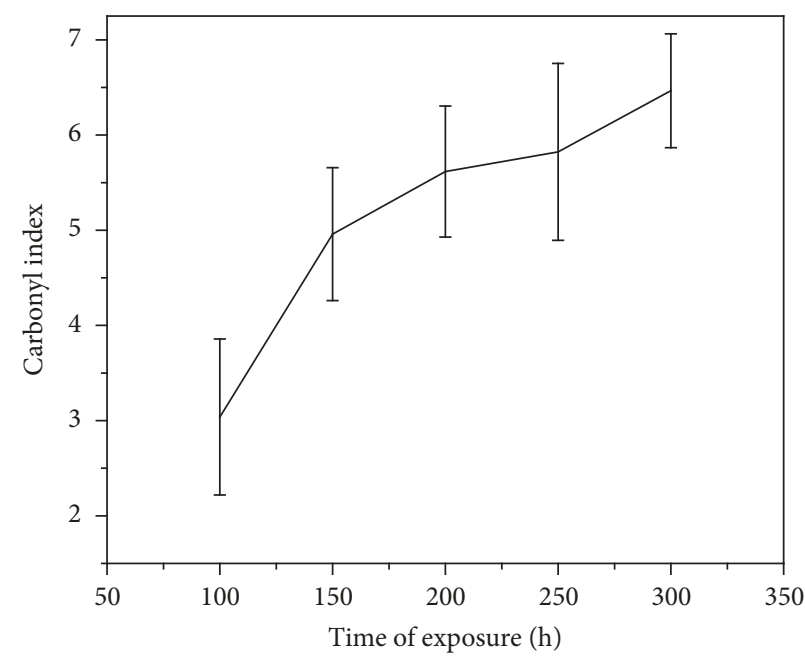

(a)

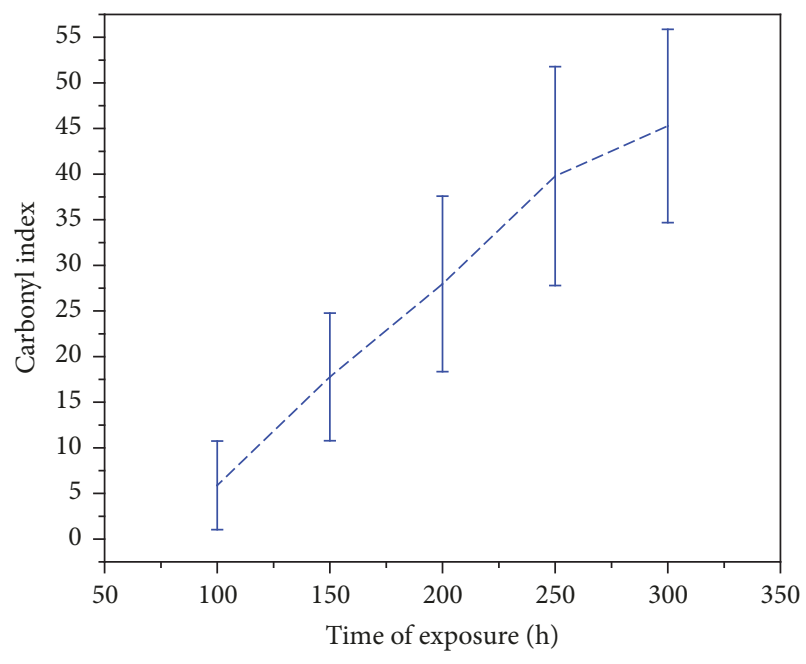

(b)

FIGURE 5: Variation of the oxo-degradable LDPE carbonyl index with time of exposure in a Xenon arc chamber calculated with (a) the total area and (b) the corrected area under the carbonyl band.

TABLE 2: Reduction of the mechanical properties of degraded material/LDPE blends compared to the neat LDPE.

\begin{tabular}{lcc}
\hline $\begin{array}{l}\text { Degraded } \\
\text { material } \\
\begin{array}{l}\text { concentration } \\
\text { [wt.\%] }\end{array}\end{array}$ & $\begin{array}{c}\text { Tensile } \\
\text { strength } \\
\text { reduction } \\
{[\%]}\end{array}$ & $\begin{array}{c}\text { Elongation } \\
\text { at break } \\
\text { reduction } \\
{[\%]}\end{array}$ \\
\hline Neat LDPE & 0 & 0 \\
1 & 47,7 & 55,67 \\
5 & 45,18 & 57,88 \\
10 & 62,36 & 70,26 \\
20 & 71,51 & 80,24 \\
50 & 68,98 & 96,36 \\
\hline
\end{tabular}

material into the LDPE matrix. Furthermore, it is observed that the standard deviation exhibited by the data is significant. The blend at 5 wt.\% showed a higher dispersion and its behavior is out of the decreasing trend.

Figure 6 also shows the reduction of the elongation at break with the incorporation of the degraded material. Likewise, the standard deviation of $5 \mathrm{wt} . \%$ blend is higher in comparison to the remaining concentrations.

The specimen with 50 wt. $\%$ of degraded material exhibited brittle fracture which means that its stiffness is higher with respect to the other concentrations. This behavior could be attributed to the chains rupture and crosslinking formations as the degraded material loading increases [12, $27,28]$. The $1,5,10$, and $20 \mathrm{wt} . \%$ specimens showed necking formation and ductile fracture as the stress applied increased [8]. The concentrations lower than $50 \mathrm{wt}$.\% exhibited a plastic deformation; however, the elongation at break was reduced considerably in comparison to the pure LDPE.

Young's modulus was also determined for the neat LDPE and its blends as the final part of the mechanical properties assessment. The variation of this property with the degraded material loading is also depicted in Figure 6(c). Considering the error bands of the plot, Young's modulus of the blends is slightly altered by the loading of the degraded material.

\subsubsection{Study of the Degraded Material/LDPE Blends Reprocess-} ing. Thermal analysis and melt flow tests were carried out to determine the reprocessing conditions of the degraded material/LDPE blends.

(1) Thermal Analysis. The melting temperatures of the neat LDPE and the degraded material/LDPE blends were obtained from the DSC analyses. To determine a new reprocessing temperature for each degraded material/LDPE blend, $T_{\text {endset }}$ was considered, assuming that the melting process is complete at this point. However, $5^{\circ} \mathrm{C}$ was added to the $T_{\text {endset }}$ to ensure the complete melting of the blends during the reprocessing. $T_{\mathrm{m}}, T_{\text {endset}}$, and $X_{\mathrm{C}}$ values of the neat LDPE and degraded material/LDPE blends are shown in Table 3. The analyses were carried out to the original blends without reprocessing as well as to the blends with three reprocessing processes.

As shown in Table 3, the variation of $T_{\mathrm{m}}$ and $T_{\text {endset }}$ is not significant, as the values are similar to those found before the reprocessing of the blends simulating the mechanical recycling conditions (high shear rate and temperature). The temperature values of the $50 \mathrm{wt} . \%$ blend with three reprocessing processes could not be obtained as the mixture did not withstand even the first reprocessing cycle. Therefore, at this concentration, the LDPE blend is not suitable for recycling.

As well, the degree of crystallinity does not vary considerably with the reprocessing of the blends that contain 0 to $10 \%$ degraded material in the LDPE. Only the blend with $20 \%$ of degraded material shows a drastic drop of the crystallinity, due to the rupture of the chains, caused by the polyethylene oxidation. This behavior modifies the structure of the blends by decreasing the initial molecular weight of the reprocessed blends [12, 29-31]. 


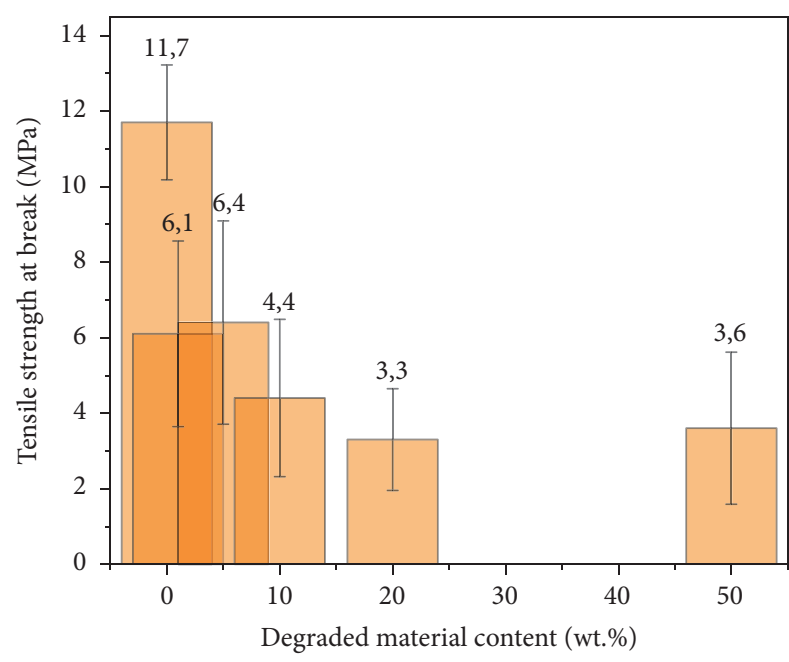

(a)

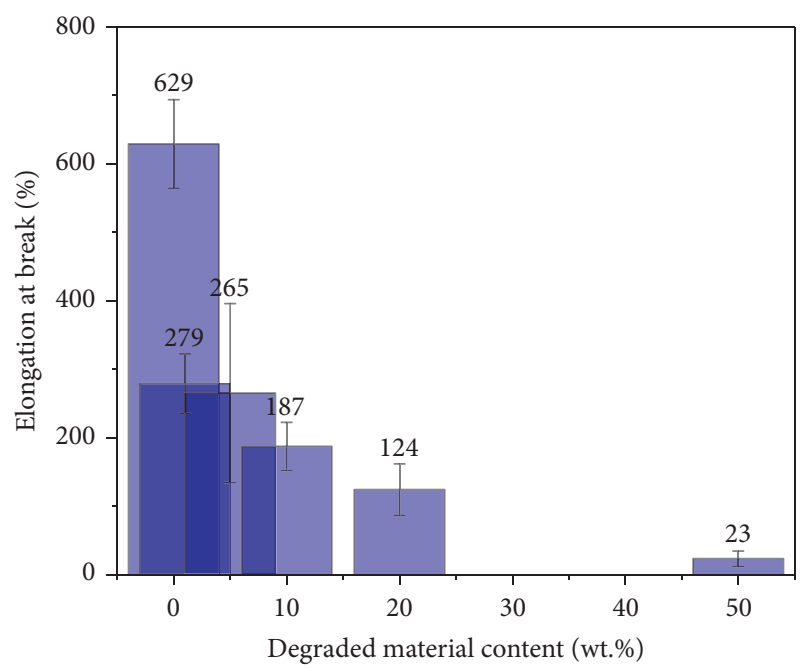

(b)

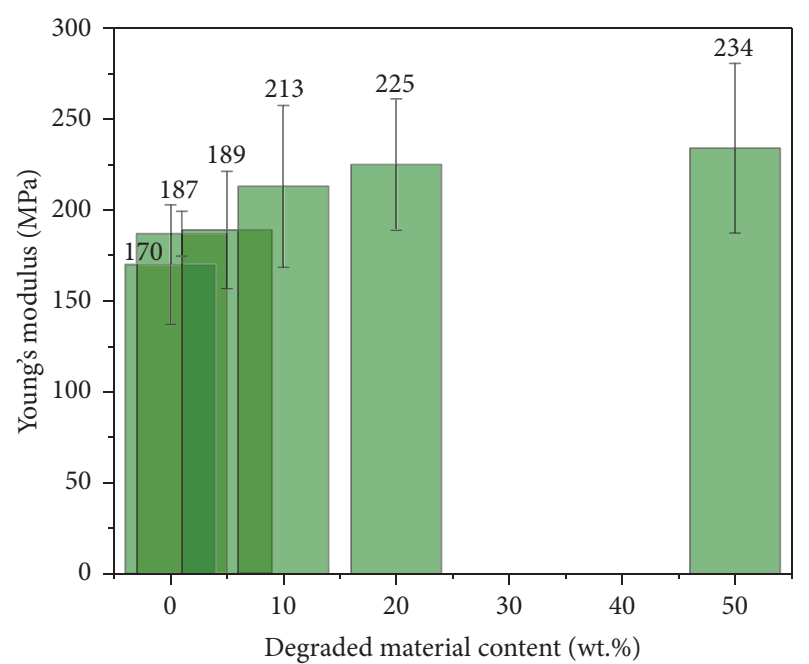

(c)

Figure 6: Effect of the degraded LDPE incorporation on the properties of degraded material/LDPE blend: (a) tensile strength at break, (b) elongation at break, and (c) Young's modulus.
TABLE 3: DSC analyses data of the neat LDPE and degraded material/LDPE blends. The third reprocessing data is also considered.

\begin{tabular}{lccc}
\hline $\begin{array}{l}\text { Concentration of } \\
\text { the degraded } \\
\text { material } \\
\text { [wt.\%] }\end{array}$ & $T_{\mathrm{m}}\left[{ }^{\circ} \mathrm{C}\right]$ & $T_{\text {endset }}\left[{ }^{\circ} \mathrm{C}\right]$ & $X_{\mathrm{C}}[\%]$ \\
\hline 0 & 114,0 & 119,5 & 23,9 \\
1 & 112,2 & 116,6 & 24,5 \\
5 & 111,6 & 115,1 & 23,3 \\
10 & 111,1 & 115 & 21,6 \\
20 & 111,3 & 114,7 & 22,3 \\
50 & 111,5 & 114,8 & 32,01 \\
\hline & Third reprocessing & \\
\hline 0 & 112,5 & 117,9 & 29,23 \\
1 & 113,8 & 119,4 & 29,9 \\
5 & 112,1 & 118,0 & 23,8 \\
10 & 112,5 & 119,1 & 24,6 \\
20 & 112,3 & 117,0 & 8,36 \\
50 & - & - & - \\
\hline
\end{tabular}

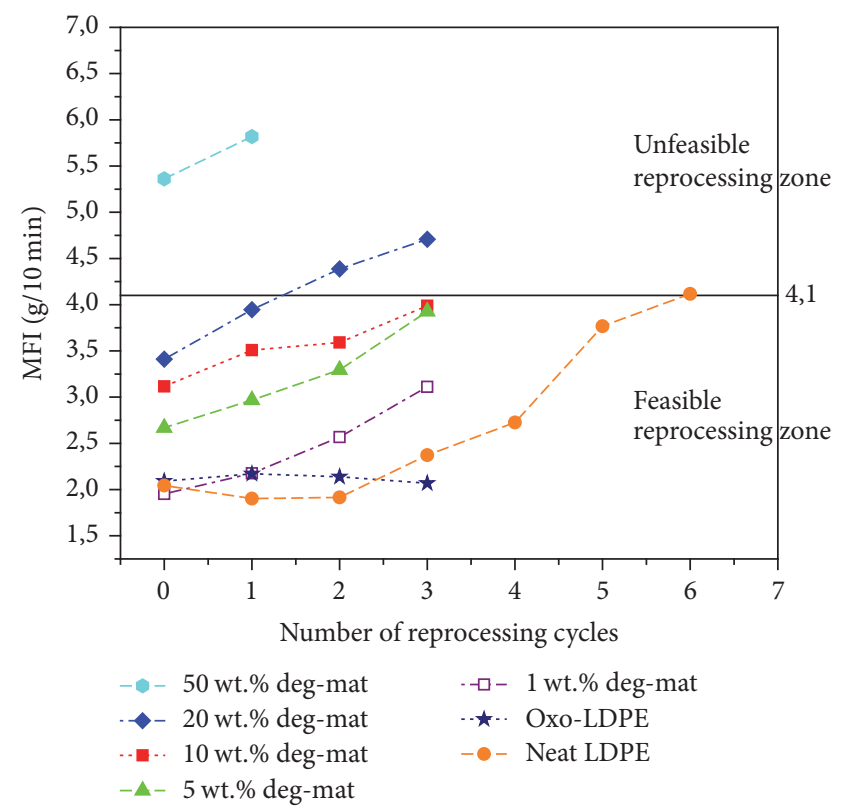

FIGURE 7: Degraded material/LDPE melt flow index with respect to the number of reprocessing cycles. The plot is divided into feasibility reprocessing zones.

(2) Melt Flow Index (MFI) Assessment. The melt flow index increases as the shear rate and processing temperature rise. This behavior was found to be the same in the degraded material/LDPE blends, neat LDPE, and oxo-degradable LDPE.

High melt flow index values are related to low polymer viscosities; thus, the material processability is negatively affected, especially in the extrusion technique [32]. It is observed in Figure 7 that the 1 wt.\% blend shows initially similar MFI values to the comparative patterns whereas the 50 wt.\% blend exhibits, even without reprocessing, a 


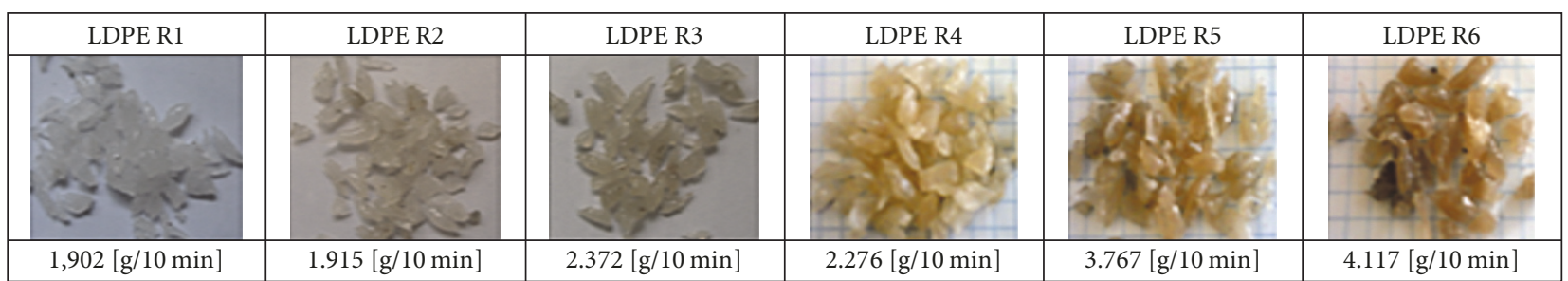

\begin{tabular}{|l|}
\hline $\mathrm{R} 0-1 \%=1,953$ \\
\hline $\mathrm{R} 1-1 \%=2,177$ \\
\hline
\end{tabular}

\begin{tabular}{|l|}
\hline $\mathrm{R} 2-1 \%=2,568$ \\
\hline $\mathrm{R} 3-1 \%=3,111$ \\
\hline $\mathrm{R} 0-5 \%=2,669$ \\
\hline $\mathrm{R} 1-5 \%=2,968$ \\
\hline $\mathrm{R} 0-10 \%=3,117$ \\
\hline $\mathrm{R} 2-5 \%=3,295$ \\
\hline $\mathrm{R} 0-20 \%=3,411$ \\
\hline $\mathrm{R} 1-10 \%=3,508$ \\
\hline $\mathrm{R} 2-10 \%=3,591$ \\
\hline
\end{tabular}

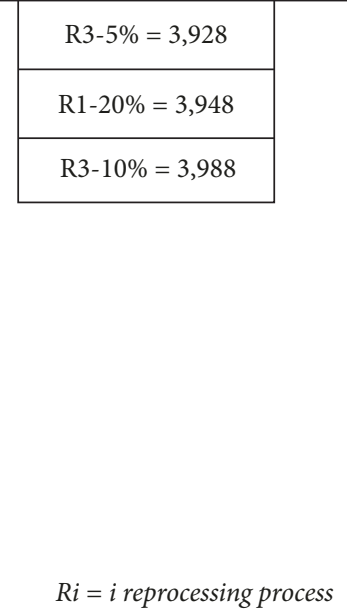

Figure 8: Comparison of the MFI values between the aged oxo-degradable/LDPE blends and the neat LDPE considering six reprocessing cycles.

higher MFI value in compassion to six-time reprocessed neat LDPE. The feasibility zone of reprocessing was set at the sixth reprocessing cycle of the neat LDPE because, during the seventh reprocessing, LDPE exhibited a higher level of degradation and flow difficulties. Therefore, the blends with MFI values higher than the sixth reprocessing were not considered as suitable materials for transformation processes.

According to Figure 7, the blends at 1, 5, and $10 \mathrm{wt} . \%$ withstand the reprocessing as their MFI values fall within the feasibility zone. These results indicate the degradation level of each blend during the reprocessing. Additionally, it was found that the $20 \mathrm{wt} . \%$ blend degrades in the first reprocessing which means that the molecular weight decreases due to polymer chains breakage $[25,32]$.

The loss of properties in each reprocessing is complemented with the tensile strength reduction assessed in Section 3.2.1. The MFI value of the $50 \mathrm{wt}$.\% blend was found to be out of the processing range with respect to the neat LDPE indicating that this blend is not suitable for recycling. The yellowing phenomenon and the variation of the neat LDPE MFI value were essential to determine the optimum amount of degraded material to be incorporated in the matrix. The reprocessing MFI values of the blends were numerically compared to neat LDPE. Also, in Figure 8, photographs of the thermal degradation after the consecutive reprocessing of the blends are shown. The yellowing effect is ascribed to the formation of the chromophores groups in the polymeric chain.

Additionally, a comparison between the MFI values of the blend reprocessing with the pure LDPE can be seen in
Figure 8. R1, R2, and R3 stand for the number of reprocessing cycles. Moreover, the attached photographs can be used to assess the degradation level of the blends visually. The LDPE-R6 photograph exhibits a significant change in color indicating the presence of chromophores groups which are responsible for the yellowing phenomenon and the oxidation of the polymer as mentioned before.

Finally, it is observed that the maximum weight percentage of aged oxo-degradable LDPE that can be incorporated and withstand three reprocessing cycles before the loss of properties was $10 \mathrm{wt} \%$.

\section{Conclusion}

The 300-hour cycle in the Xenon arc test chamber was set as the UV-exposure time limit for the oxo-degradable LDPE to prevent the formation of the hydroperoxides groups.

The increasing of the oxo-degradable LDPE content altered the neat LDPE mechanical properties considerably. The reduction of the LDPE elasticity, plasticity, and tensile strength was evidenced due to the chains rupture and crosslinking of the LDPE molecular structure caused by the oxidation of the aged plastic.

High weight percentages of the oxo-degradable LDPE, such as 20 and $50 \mathrm{wt} . \%$, originated a significant loss (>50\%) of mechanical properties of pure LDPE.

The neat LDPE melting temperatures exhibited a slight variation with the incorporation of $1,5,10,20$, and $50 \mathrm{wt} . \%$ of the degraded material.

The melt flow index increases with the incorporation of the aged oxo-degradable LDPE. The $50 \mathrm{wt} \%$ blend is not 
suitable for reprocessing in comparison to the neat LDPE. The $20 \mathrm{wt}$ \% blend withstands only one reprocessing cycle.

According to the mechanical, thermal, and reprocessing studies, the 1, 5, and $10 \mathrm{wt} . \%$ degraded material/LDPE blends showed the lower negative impact on the neat LDPE matrix. However, the loss of properties of the mentioned blends was significant. Therefore, the use of these formulations as recycling products is not recommended.

Mechanical testing and MFI determination are the most appropriate evaluations to detect any other recycled material present in the LDPE matrix in comparison to DSC.

\section{Conflicts of Interest}

The authors declare that they have no conflicts of interest.

\section{References}

[1] S. Selke, R. Auras, T. A. Nguyen, E. Castro Aguirre, R. Cheruvathur, and Y. Liu, "Evaluation of Biodegradation-Promoting Additives for Plastics," Environmental Science \& Technology, vol. 49, no. 6, pp. 3769-3777, 2015.

[2] S. Miertus, Introduction to the ICS-UNIDO Programes and Activities in the Area of Pure ans Applied, Trieste, 2000.

[3] O. A. Othman, S. Faiz, and A. Muhammad, "Study of natural and accelerated weathering on mechanical properties of antioxidants modified low density polyethylene films for greenhouse," International Journal of Polymer Science, pp. 1-5, 2014.

[4] A. Martínez-Romo, R. González-Mota, J. J. Soto-Bernal, and I. Rosales-Candelas, "Investigating the degradability of HDPE, LDPE, PE-BIO, and PE-OXO films under UV-B radiation," Journal of Spectroscopy, vol. 2015, Article ID 586514, pp. 1-6, 2015.

[5] X. Quecholac, M. Garcia, R. Espinoza, A. Vásquez, M. Beltran, and A. Cisneros, "Biodegradation of compostable and oxodegradable plastic films," in Proceedings of the 4th International Symposium on Environmental Biotechnology and Engineering2014, pp. 1-6, 2016.

[6] E. Chiellini, Enviromentally Degradable Plastics: An Overview on Present Status and Perspectives, Pisa, 2000.

[7] E. Matei, M. Râps, Á. A. Andras et al., "Recycled polypropylene improved with thermoplastic elastomers," International Journal of Polymer Science, vol. 2017, pp. 1-10, 2017.

[8] Y. G. Ángeles-López, A. M. Gutiérrez-Mayen, M. Velasco-Pérez, M. Beltrán-Villavicencio, A. Vázquez-Morillas, and M. CanoBlanco, "Abiotic degradation of plastic films," Journal of Physics: Conference Series, vol. 792, p. 012027, 2017.

[9] H. Castellon, Plásticos oxo-degradables vs. plásticos biodegradables ¿cuál es el camino? Caracas, 2009.

[10] A. Vázquez-Morillas, M. Beltrán-Villavicencio, J. C. AlvarezZeferino et al., "Biodegradation and Ecotoxicity of Polyethylene Films Containing Pro-Oxidant Additive," Journal of Polymers and the Environment, vol. 24, no. 3, pp. 221-229, 2016.

[11] T. Ojeda, "Polymers and the Environment," in Polymer Science, pp. 1-33, InTech, Ankara, Turkey, 2013.

[12] F. Quiroz, F. Cadena, L. Sinche, I. Chango, and M. Aldás, "Estudio de la degradación de polímeros oxo-biodegradables," Revista Politécnica, vol. 30, no. 1, pp. 179-191, 2009.
[13] K. Snyder, C. Murray, T. Laredo, and B. Wolff, "The effect of exposure to Pyrinex 480 on the degradation of clear oxodegradable polyethylene agricultural films," Polymer Degradation and Stability, vol. 134, pp. 328-339, 2016.

[14] A. Benitez, J. Sanchez, M. Arnal, A. Muler, and O. Rodriguez, "Abiotic degradation of LDPE and LLDPE formulated with a pro-oxidant," Polymer Degradation and Stability, pp. 490-501, 2012.

[15] T. Noreen, J. Clarke, A. McLauchin, and S. Patrick, Assesing the environmental ofo oxo-degradables plastics across their life cycle, DEFRA, Londres, 2010.

[16] X. Liu, C. Gao, P. Sangwan, L. Yu, and Z. Tong, "Accelerating the degradation of polyolefins through additives and blending," Journal of Applied Polymer Science, vol. 131, no. 18, Article ID 40750, pp. 9001-9015, September 2014.

[17] M. Wrona, P. Vera, D. Pezo, and C. Nerín, "Identification and quantification of odours from oxobiodegradable polyethylene oxidised under a free radical flow by headspace solid-phase microextraction followed by gas chromatography-olfactometry-mass spectrometry," Talanta, vol. 172, pp. 37-44, 2017.

[18] E. Chiellini, A. Corti, S. D’Antone, and R. Baciu, "Oxo-biodegradable carbon backcone polymers-Oxidative degradation of polyethylene under accelerated test conditions," in Polymer Degradation and Stability, pp. 1-9, 2006.

[19] A. Ammalaa, S. Batemana, K. Deana et al., "An overview of degradable and biodegradable polyolefins," in Progress in Polymer Science, pp. 1015-1049, 2010.

[20] N. L. Thomas, J. Clarke, A. R. McLauchlin, and S. G. Patrick, "Oxodegradable plastics: degradation, environmental impact and recycling," Proceedings of the Institution of Civil Engineers - Waste and Resource Management, vol. 165, no. 3, pp. 133-140, 2012.

[21] M. San Andrés, R. Chércoles, J. De la Roja, and M. Gómez, "Factoresresponsables de la degradación química de los polímeros. Efectos provocados por la radiación lumínica sobre algunosmateriales utilizados en conservación: primeros resultados," 21 Octubre 2010, http://ccfib.mcu.es/patrimonio/docs/MC/ POLYEVART/FactrespXIReinaSof.pdf.

[22] Dow, Plásticos Básicos-Guía de productos y solicitudes, 2010.

[23] Symphony environmental, "Plastimarket," Octubre 2011, http:// plastimarket.com/wp-content/uploads/2015/01/ADITIVOSHYMPONY-D2W.pdf.

[24] P. Roy, P. Surekha, C. Rajagopal, S. Chatterjee, and V. Choudhary, "Studies on the photo-oxidative degradation of LDPE films in the presence of oxidised polyethylene," Polymer Degradation and Stability, vol. 92, no. 6, pp. 1151-1160, 2007.

[25] J. Rabek, Polymer Photodegradation, Londres: Springer Science+Business Media Dordrecht, 1995.

[26] L. Chen, S. Yamane, T. Sago et al., "Experimental and modeling approaches for the formation of hydroperoxide during the auto-oxidation of polymers: Thermal-oxidative degradation of polyethylene oxide," Chemical Physics Letters, vol. 657, pp. 8389, 2016.

[27] C. David, "Thermal degradation ofpolymers," in Comprehensive Chemical Kinetics, pp. 1-173, Elsevier, Amsterdam, The Netherlands, 1975.

[28] K. Balani, V. Verma, A. Agarwal, Narayan, and Roger, Biosurfaces: A Materials Science and Engineering Perspective, John Wiley \& Sons, Inc, Hoboken, NJ, USA, 2015.

[29] F. La Mantia, M. Morreale, L. Botta, M. Mistretta, M. Ceraulo, and R. Scaffaro, "Degradation of polymers blends: a brief review," in Polymer Degradation and Stability, pp. 1-35, 2017. 
[30] A. Göpferich, "Mechanisms of polymer degradation and erosion," Biomaterials, vol. 17, no. 2, pp. 103-114, 1996.

[31] M. Musioł, J. Rydz, H. Janeczek, I. Radecka, G. Jiang, and M. Kowalczuk, "Forensic engineering of advanced polymeric materials Part IV: Case study of oxo-biodegradable polyethylene commercial bag - Aging in biotic and abiotic environment," Waste Management, vol. 64, pp. 20-27, 2017.

[32] M. Niaounakis, Biopolymers Reuse, Recycling, and Disposal, Elsevier, Amestrdam, The neitherlands, 2013. 


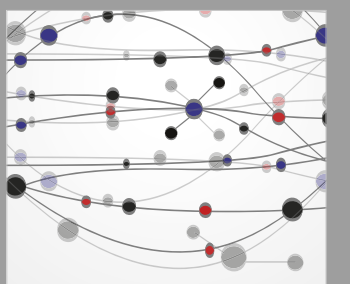

The Scientific World Journal
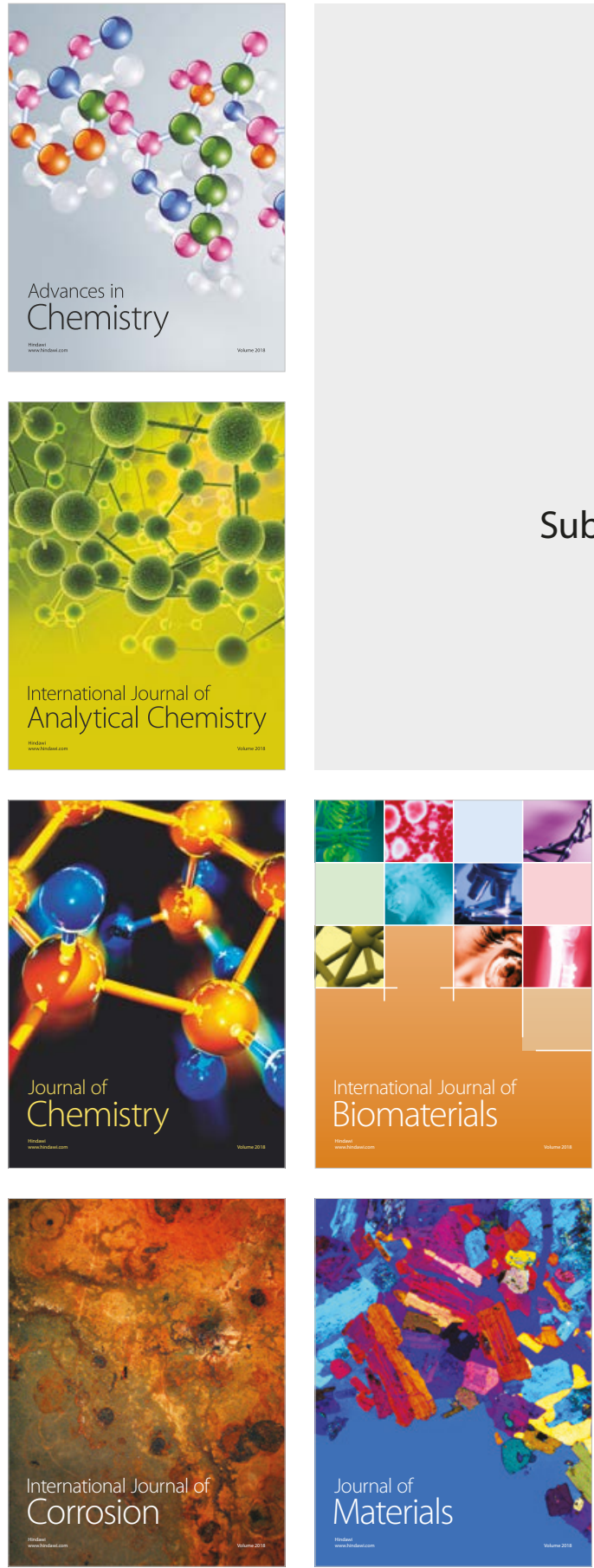

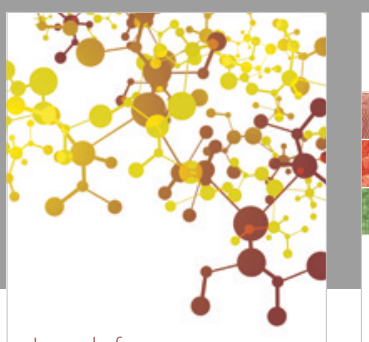

Journal of

Applied Chemistry
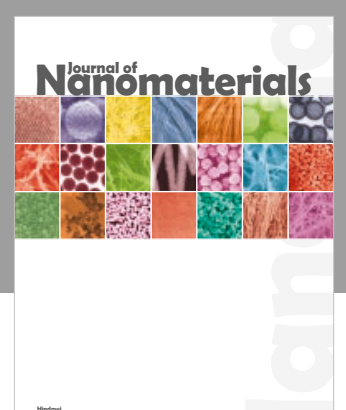

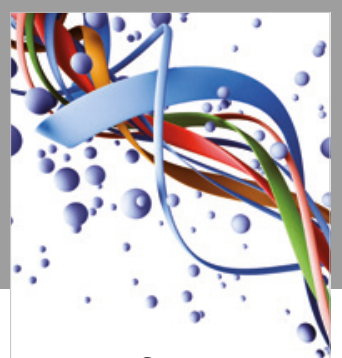

Scientifica

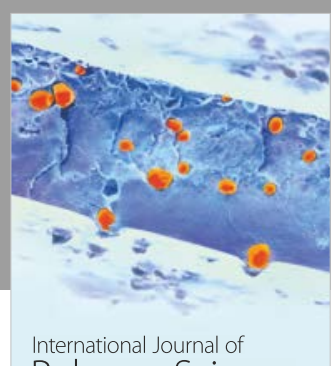

Polymer Science

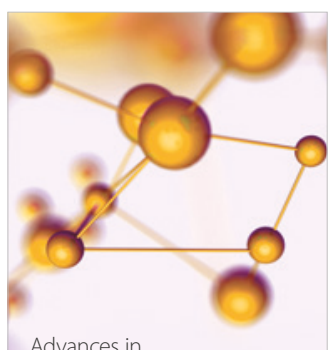

Physical Chemistry
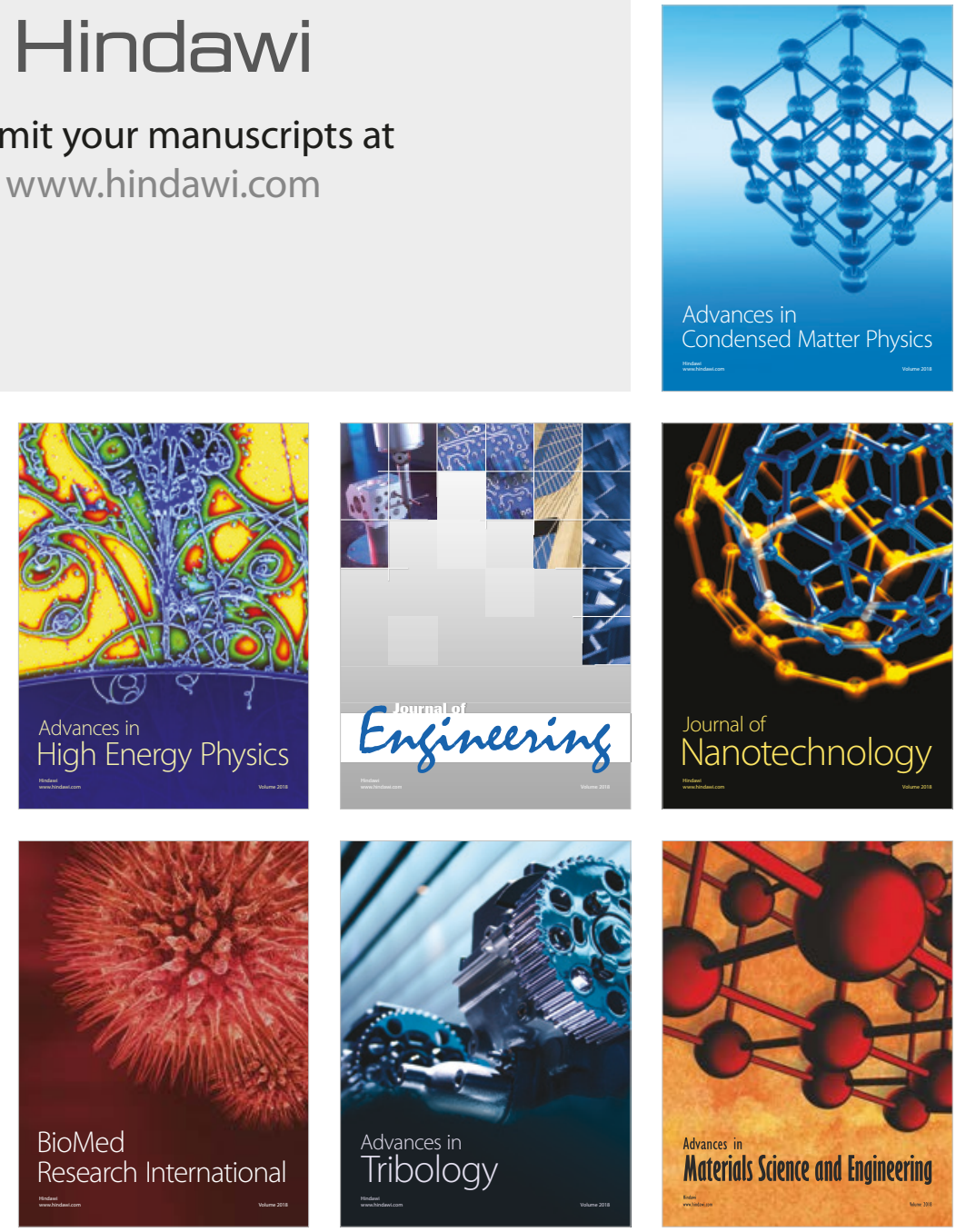